\title{
Migration And The Quality Of Life
}

\author{
JAMES B. KAU* AND C. F. SiRmans**
}

\section{INTRODUCTION}

Theoretical and econometric models of migration behavior are usually based on the proposition that population movements are a function of economic factors. Previous studies of gross migration have concentrated on the investment framework ${ }^{1}$ with little emphasis on quality-of-life factors. $^{2}$ This has occurred because of the lack of available data to measure relative quality of life differences among regions. Recently a study by Liu [1974] has made available indices which measure the quality of life of a region. This paper examines the impact that variations in the quality of life have on migration.

A model is formulated for the estimation of migration between the nine census divisions and the various states using 1960 and 1970 census data. ${ }^{3}$ This study estimates a model for migrants by race in the United States who moved during a five year period prior to the census (current migrants) and for migrants who were enumerated in 1960 in a state different from the region in which they were born (lifetime migrants). The explanatory variables are used to measure the responsiveness of recent and lifetime migrants to factors which may effect their decision to move.

As discussed by Levy and Wadycki [1972], there are several reasons why the influence of the explanatory variables may differ between current and past migration flows. These differences result from changes over time in the consumption patterns of migrants and in the benefits and costs of migration. Current migrants, as a result of increased income, may desire to maximize a utility function which includes not only the economic considerations but also the quality of life factors resulting from migration. The costs of migration may have changed over time due to changes in the ability of the migrant to assimilate information, such as improved education, and from the increased availability of information from previously migrated friends and relatives. Also with improved transportation systems, the direct money costs of moving have been reduced. The results presented in this paper indicate considerable differences between current and lifetime migrants in their response to differences in the quality of life among states. The model supports the contention that migrants respond in a rational way to alternative opportunities.

\footnotetext{
*University of Georgia.

**University of Illinois at Champaign-Urbana.

\#This is a joint paper: order of the authors' names was determined randomly.
} 


\section{THEORETICAL FRAMEWORK}

The model used in this study assumes that migrants desire to maximize utility subject to the constraints of income and prices at each possible destination. The information available to each individual varies and thus each migrant forms different subjective predictions of the expected net benefit from migration. An equation expressing such a framework is:

$\mathrm{U}=\mathrm{U}\left(\mathrm{x}_{1} \ldots \mathrm{x}_{\mathrm{n}}\right)-\sum_{\mathrm{j}=1}^{\mathrm{m}}\left[\lambda_{\mathrm{j}} \delta_{\mathrm{j}}\left(\mathrm{I}_{\mathrm{j}}-\sum_{\mathrm{k}=1}^{\mathrm{n}} \mathrm{P}_{\mathrm{kj}} \mathrm{X}_{\mathrm{kj}}-\mathrm{M}_{\mathrm{j}}\right)\right]$

where:

$\mathrm{n}=$ number of consumption goods being considered,

$\mathrm{m}=$ number of possible destinations

$\mathrm{U}\left(\mathrm{x}_{1} \ldots \mathrm{x}_{\mathrm{n}}\right)=$ utility achieved from the consumption goods,

$\lambda_{j}=$ discrete choice parameter which has a value of 1 for the selected destination and a value of 0 for all other nonselected destinations,

$I_{\mathbf{j}}=$ expected income for each destination,

$\mathrm{P}_{\mathbf{k} \mathbf{j}}=$ set of prices for each destination,

$\delta_{\mathrm{j}}=$ the uncertainty associated with the expected value of $I_{j}$ and $P_{k j}$ for each destination,

$\mathrm{M}_{\mathrm{j}}=$ direct moving costs for each destination

Equation (1) is couched in an integer programming framework with the selected destination being a discrete decision. ${ }^{4}$ The selected region with a $\lambda$ value equal to 1 is the binding constraint on the utility function. The migrant thus selects that destination which maximizes utility. Hence investment behavior, in terms of achieving the highest possible income, and utility maximization, in terms of selecting the optimum mixture of consumption goods are incorporated into one framework.

Insight into the trade-offs that occur with the selection of any destination is demonstrated by equation (1). The decision to move is based on the interrelationships between investment opportunities and the quality of life. The existence of trade-offs suggest that destinations with the greatest possible net return on investment may not necessarily have more migration. Thus to predict the extent of migration and the net effect of investment opportunities it is necessary to hold constant the quality-of-life variations among regions.

\section{METHODOLOGY}

Recent literature on migration has been concerned with the influence of past migration flows (lifetime migration) on current migration pat- 
terns. ${ }^{5}$ Nelson [1959] hypothesized that a migrant is more likely to receive information about a region to which friends and relatives have previously migrated. Also, the costs of migration, both real and psychic, could be reduced as a result of being near friends and relatives. In this respect, the lifetime migration flows (migrant stock) variable is used to explain current patterns and is expected to be positively related to the current flows.

The migrant stock variable is a measure of total lifetime migration and hence a function of the same variables affecting current migration. This leads to certain specification problems concerning the form of the migration model to be estimated. The relationship between migration flows and migrant stock makes it highly unlikely that the traditional Greenwood [1969] model would be the correct specification. The residuals from this traditional OLS single equation model would probably be highly correlated. Yet it is probably unnecessary to use a full structural simultạneous equation model.

The endogenous coefficient, current migration flows, will be insignificant since current flows have no effect on past migration. Therefore, while the traditional single equation model is too simplistic, the full simultaneous model is too complex. Thus, what is needed is a model which lies between the two. One such model is the recursive system developed by Wold [1954].

The full structural simultaneous equation model can be restricted. One set of restrictions leads to a special case of the full structural model known as a recursive system. The structural equations are ordered in this system such that the first equation has only one endogenous variable, the second equation has two endogenous variables, and so forth. The system could be represented as:

$\mathrm{Y}_{1}$

$$
=\beta_{11} \mathrm{X}_{11}+\beta_{12} \mathrm{X}_{12}+\ldots+\beta_{1 \mathrm{~m}} \mathrm{X}_{1 \mathrm{~m}}+\varepsilon_{1}
$$

$\alpha_{21} \mathrm{Y}_{1}+\mathrm{Y}_{2}$

$$
=\beta_{21} \mathrm{X}_{21}+\beta_{21} \mathrm{X}_{21}+\ldots+\beta_{2 \mathrm{~m}} \mathrm{X}_{2 \mathrm{~m}}+\varepsilon_{2}
$$

$\alpha_{n 1} Y_{1}+\alpha_{n 2} Y_{2}+\ldots+Y_{n}=\beta_{n 1} X_{n 1}+\beta_{n 2} X_{n 2}+\ldots+\beta_{n m} X_{n m}+\varepsilon_{n}$

where $\alpha$ represents the coefficients on the $\mathrm{n}$ endogenous variables, $B$ represents the coefficients on the $m$ exogenous variables and $\varepsilon$ represents the disturbance term for the equations. The Y's represent migration flows in the model while the X's represents quality of life or migrant characteristic variables. There would be $\mathrm{T}$ periods of observations on $\mathrm{Y}$ and $\mathrm{X}$.

If the disturbances of the equations in this type of model are independent, then concerning random components, each equation is unrelated 
to the preceding equations. There are no problems with the first equation since there is only one endogenous variable. The dependent variable in the second equation is determined by the exogenous variables, $\mathrm{Y}_{1}$ and $\varepsilon_{2}$. The random component of $Y_{1}$ is $\varepsilon_{1}$, which is assumed independent of $\varepsilon_{2}$, thus $Y_{1}$ may be regarded as predetermined with respect to $Y_{2}$. Similar reasoning can be continued for the rest of the equations in the system.

Hence, all of the variables in any particular equation except the dependent variable can be treated as being predetermined. The ordinary least squares estimator gives unbiased estimates under these conditions. It is thus unnecessary to use a two-stage least squares estimator, which is important due to several difficulties involved in using a two-stage least squares approach. The replacing of endogenous variables with their expectations in the second stage is one such difficulty. A great deal of inefficiency is introduced into the estimation in the second stage if these expectations are poor predictors. Another difficulty with the two-stage least squares estimator stems from multicollinearity in the data as well as multicollinearity associated with the estimation process. The first stage regresses the endogenous variables on all of the exogenous variables in the system. In a migration model, it is likely the exogenous variables are highly related. Another source of multicollinearity comes from the stage when the endogenous variables are replaced by their expectations. These expectations are linear combinations of the exogenous variables.

The recursive system is a model which lies between the single equation regression model and the full structural simultaneous equation model. The recursive system combines the simple estimation technique of the single equation model with parts of the simultaneity of the full structural simultaneous equation model.

The recursive system unlike the full structural simultaneous equation model does require an ordering of the dependent variables. The most logical ordering procedure would be an ordering based on time. If the dependent variables were determined at different times, they could be ordered to let the dependent variable which is determined first be in the first equation. This procedure could be followed until the dependent variable which could be expected to be determined last would be in the last equation. Fortunately it is easy to justify an ordering based on time in a migration model. The specification of the migration model as a recursive system provides information on the determinants of lifetime and current migration as well as the influence of past migration on current flows.

\section{DATA AND EMPIRICAL MODEL}

The theoretical model discussed in Section II can be combined with the recursive model outlined in Section III and expressed in an empirical framework similar to other econometric studies of migration. ${ }^{6}$ The equations to be estimated are: 


$$
\begin{aligned}
& M S_{i j}=f\left(D_{i j}, O A_{j}, \text { random errors }\right) \\
& M_{i j}=f\left(D_{i j}, O A_{i}, M_{i j}, \text { random errors }\right)
\end{aligned}
$$

and

$$
\begin{aligned}
\mathrm{MS}_{\mathrm{ij}}= & \mathrm{f}\left(\mathrm{D}_{\mathrm{ij}}, \mathrm{IS}_{\mathrm{ij}}, \mathrm{IQ}_{\mathrm{ij}}, \mathrm{LC}_{\mathrm{ij}}, \mathrm{AG}_{\mathrm{ij}}, \mathrm{TECH}_{\mathrm{ij}}, \mathrm{EC}_{\mathrm{ij}},\right. \\
& \left.\mathrm{ED}_{\mathrm{ij}}, \mathrm{HW}_{\mathrm{ij}} \mathrm{SLG}_{\mathrm{ij}}, \text { random errors }\right) \\
\mathrm{M}_{\mathrm{ij}}= & \mathrm{f}\left(\mathrm{D}_{\mathrm{ij}}, \mathrm{MS}_{\mathrm{ij}}, \mathrm{IS}_{\mathrm{ij}}, \mathrm{IQ}_{\mathrm{ij}}, \mathrm{LC}_{\mathrm{ij}}, \mathrm{AG} \mathrm{G}_{\mathrm{ij}}, \mathrm{TECH}_{\mathrm{ij}}, \mathrm{EC}_{\mathrm{ij}},\right. \\
& \left.\mathrm{ED}_{\mathrm{ij}}, \mathrm{HW}_{\mathrm{ij}} \mathrm{SLG}_{\mathrm{ij}}, \text { random errors }\right)
\end{aligned}
$$

where:

$\mathrm{MS}_{\mathrm{ij}}=$ the total, white, and black lifetime migration from $\mathrm{i}$ to $\mathrm{j}$, 1960 ,

$\mathbf{M}_{\mathrm{ij}}=$ either total, white, or black migrants who were residing in region $\mathrm{i}$ in 1965 and had migrated to state $\mathrm{j}$ by 1970 expressed as a percentage of the total out-migration from the origin (i) ${ }^{7}$

$\mathrm{OA}_{j}=$ overall quality of life index for destination $\mathbf{j}$,

$D_{i j}=$ the road distance in miles between SMSA with the greatest population in origin $i$ to that of destination $j$,

$\mathrm{IS}_{\mathrm{ij}}=$ individual status, i.e., factors which promote maximum development of individual capabilities,

$\mathrm{IQ}_{\mathrm{ij}}=$ individual equality such as factors describing current economic discrimination against race and sex,

$\mathrm{LC}_{\mathrm{ij}}=$ living conditions such as general, social, and environmental living conditions, plus availability of facilities,

$\mathrm{AG}_{\mathrm{ij}}=$ agriculture production including factors pertaining to commercial operations,

$\mathrm{TECH}_{\mathrm{ij}}=$ technological development including factors reflecting the availability of scientific manpower, and the promotion and encouragement of research,

$\mathrm{EC}_{\mathrm{ij}}=$ economic status such as cost-adjusted income figures, employment, and resources,

$\mathrm{ED}_{\mathrm{ij}}=$ educational development, factors measuring educational background and accomplishments,

$\mathrm{HW}_{\mathrm{ij}}=$ health and welfare, factors depicting available facilities and services of medical care and welfare,

$\mathrm{SLG}_{i j}=$ state and local governments. Factors representing informed citizenry, professional classes and performance of the administration.

All the aforementioned variables except $\mathrm{M}_{\mathrm{ij}}, \mathrm{MS}_{\mathrm{ij}}$, and $\mathrm{D}_{\mathrm{ij}}$ were taken from Liu's study (1974) on the quality of life and are expressed as the ratio of destination to origin values. ${ }^{8}$ 
Liu's quality-of-life (QOL) indexes are based on factors universally accepted as principal components in one's well-being. The raw data were converted into an ordinal scale and divided into basic structural groups with all variables in the same category weighted equally. The results were the nine QOL component indicators expressed above in the listing of the variables. In addition an overall index (OA) was constructed based on the weighted average of the nine components with each carrying an equal weight. The indexes were used in Liu's study to rank individual states on their relative quality-of-life and are used in this study to test the sensitivity of migrants to quality-of-life variations among states.

As discussed by Liu (1974), the correlation values of the various components of the quality-of-life index are quite low. The highest correlation coefficient was between economic status and state and local governments, $\mathrm{r}=.78$. Virtually no correlation exists between economic equality and economic status, between economic equality and agricultural production, between agricultural production and in the health and welfare indicators; $r=.17$. Among the nine indicators the correlation coefficients are generally below 0.40 .

\section{EMPIRICAL RESULTS}

There are two comparisons to be made. One is between lifetime and current migration and the other between white and black movements. All the coefficients in Table I and II were estimated by ordinary least squares in a recursive framework. A double-logarithmic form was utilized for estimation of Table II since the coefficients are then interpretable as elasticities.

Table I presents empirical estimates of the determinants of current and lifetime migration for blacks and whites using only distance, migrant

TABLE I

MIGRATION AND OVERALL QUALITY OF LIFE REGRESSION RESULTS ${ }^{a}$

\begin{tabular}{lcccrrr}
\hline \multicolumn{1}{c}{ Variables } & Total & $\begin{array}{c}\text { Lifetime } \\
\text { White }\end{array}$ & Black & Total & $\begin{array}{c}\text { Current } \\
\text { White }\end{array}$ & Black \\
\hline Constant & .447 & .262 & .185 & .008 & .010 & -.001 \\
& $(1.45)$ & $(.92)$ & $(4.68)$ & $(1.21)$ & $(1.68)$ & $(-0.33)$ \\
$\begin{array}{l}\text { Distance } \\
\left(\mathrm{D}_{\mathrm{ij}}\right)\end{array}$ & -1.80 & -1.827 & -1.568 & -.313 & -.317 & -.207 \\
$\begin{array}{l}\text { Migrant } \\
\quad \text { Stock }\left(\mathrm{MS}_{\mathrm{ij}}\right)\end{array}$ & - & - & - & .172 & .164 & .136 \\
Overall & 1.59 & 2.034 & -1.963 & .772 & .639 & 1.016 \\
$\quad \mathrm{QOL}\left(\mathrm{OA}_{\mathrm{j}}\right)$ & $(1.90)$ & $(2.35)$ & $(-2.01)$ & $(2.51)$ & $(2.06)$ & $(2.47)$ \\
\hline $\mathrm{R}^{2}$ & .12 & .11 & .12 & .26 & .25 & .12 \\
d.f. & 438 & 438 & 431 & 437 & 437 & 430 \\
\hline
\end{tabular}

at-values are in parenthesis; coefficients represent point elasticities. 
stock and the overall quality-of-life index. These estimates are used to explore the responsiveness of migrants to the quality-of-life index. If the coefficients are significant then investigation into the component parts would be of value.

The distance variables $\left(D_{i j}\right)$ is a proxy to measure costs of moving and to capture the effect of possible cultural changes and information availability. Earlier migrants faced higher transportation cost and communication technology was such that earlier migrants experienced greater cost in acquiring information. As was found by Levy and Wadycki [1972] the distances coefficient is negative in all cases and is greater for lifetime migrants. The distance elasticity for lifetime migrants is also higher because of the inclusion of the migrant stock variable in the current migration equations. As pointed out by Greenwood [1969] the inclusion of migrant stock (past migrants) into the migration equation captures the influence that friends and relatives have on the migration rate and thus reduces the role of distance as a proxy for information cost.

The overall quality-of-life coefficients $\left(\mathrm{OA}_{j}\right)$ are positive and significant in all cases except for black lifetime migrants which is significantly negative. This indicates that migrants are affected by quality-of-life considerations in locational choice. The above index is an aggregated measure and leaves unanswered the question of what type of quality attracts migrants? Is more weight given to educational development, social and environmental living conditions, or to potential economic status? These questions are answered by the equations in Table II. These results are for current and lifetime migrants with the quality-of-life index broken down into the previously described components. The equations in Table II using the disaggregated quality-of-life components explained a large portion of the variance for current migration with $\mathrm{R}^{2}$ 's of .80 and .74 for white and black current migrants. The $\mathrm{R}^{2}$ 's for lifetime migrants are lower reflecting the exclusion of any type of migrant stock variable.

The distance variable for lifetime migrants is significantly negative and produces the greatest reduction in the residual variance. Current migrants have significant positive coefficients reflecting, as discussed above, the influence of the migrant stock variable which is included in the second stage of the recursive system. The inclusion of migrant stock and the quality-of-life indices reduces the negative impact of distance. ${ }^{9}$ The importance of distance in the lifetime equation suggest that past migrants were more sensitive to transportation cost than current migrants. The introduction of migrant stock in the current equations indicates that the impact of transportation costs on migration has possibly decreased over time and the affect of information from friends and relatives on locational decisions has increased. These conclusions are tentative since only a complete set of time series data would test and separate the relative impact of distance and migrant stock.

The results for the components of the quality-of-life index demonstrates significant differential responses between current and lifetime 
TABLE II

MIGRATION AND THE QUALITY OF LIFE: 1970 REGRESSION RESULTS FOR LIFETIME AND CURRENT MIGRANTS ${ }^{a}$

\begin{tabular}{|c|c|c|c|c|c|c|}
\hline Variables & Total & $\begin{array}{l}\text { Lifetime } \\
\text { White }\end{array}$ & Black & Total & $\begin{array}{l}\text { Current } \\
\text { White }\end{array}$ & Black \\
\hline Constant & $\begin{array}{r}12.346 \\
(85.95)\end{array}$ & $\begin{array}{r}12.188 \\
(85.48)\end{array}$ & $\begin{array}{r}9.381 \\
(48.73)\end{array}$ & $\begin{array}{r}-10.739 \\
(-49.96)\end{array}$ & $\begin{array}{r}-10.721 \\
(-48.94)\end{array}$ & $\begin{array}{r}-8.087 \\
(-42.10)\end{array}$ \\
\hline$D_{i j}$ & $\begin{array}{r}-1.646 \\
(-13.26)\end{array}$ & $\begin{array}{r}-1.521 \\
(-12.84)\end{array}$ & $\begin{array}{r}-2.118 \\
(-12.71)\end{array}$ & $\begin{array}{r}0.105 \\
(2.30)\end{array}$ & $\begin{array}{r}0.097 \\
(1.88)\end{array}$ & $\begin{array}{r}0.237 \\
(3.19)\end{array}$ \\
\hline $\mathrm{MS}_{\mathrm{ij}}$ & - & - & - & $\begin{array}{r}0.565 \\
(33.37)\end{array}$ & $\begin{array}{r}0.570 \\
(32.61)\end{array}$ & $\begin{array}{r}0.421 \\
(22.31)\end{array}$ \\
\hline $\mathrm{IS}_{\mathrm{ij}}$ & $\begin{array}{l}1.129 \\
(2.12)\end{array}$ & $\begin{array}{r}1.248 \\
(2.36)\end{array}$ & $\begin{array}{c}0.602 \\
(0.83)\end{array}$ & $\begin{array}{r}-0.086 \\
(-0.46)\end{array}$ & $\begin{array}{l}-0.170 \\
(-0.88)\end{array}$ & $\begin{array}{c}0.246 \\
(0.88)\end{array}$ \\
\hline $\mathrm{IQ}_{\mathrm{i}, \mathrm{j}}$ & $\begin{array}{r}0.096 \\
(0.18)\end{array}$ & $\begin{array}{r}0.120 \\
(0.23)\end{array}$ & $\begin{array}{r}0.099 \\
(0.12)\end{array}$ & $\begin{array}{r}-0.397 \\
(-2.15)\end{array}$ & $\begin{array}{r}-0.358 \\
(-1.89)\end{array}$ & $\begin{array}{r}-1.028 \\
(--3.75)\end{array}$ \\
\hline $\mathrm{LC}_{\mathrm{i}, \mathrm{i}}$ & $\begin{array}{l}-1.339 \\
(-2.23)\end{array}$ & $\begin{array}{c}-1.502 \\
(-2.52)\end{array}$ & $\begin{array}{c}-0.006 \\
(-0.01)\end{array}$ & $\begin{array}{c}0.475 \\
(2.24)\end{array}$ & $\begin{array}{r}0.639 \\
(2.94)\end{array}$ & $\begin{array}{l}-0.983 \\
(-3.09)\end{array}$ \\
\hline $\mathrm{AG}_{\mathrm{i}, \mathrm{j}}$ & $\begin{array}{r}0.597 \\
(2.33)\end{array}$ & $\begin{array}{c}0.603 \\
(2.37)\end{array}$ & $\begin{array}{c}0.648 \\
(1.88)\end{array}$ & $\begin{array}{r}-0.581 \\
(-6.41)\end{array}$ & $\begin{array}{l}-0.571 \\
(-6.15)\end{array}$ & $\begin{array}{l}-0.684 \\
(-5.09)\end{array}$ \\
\hline $\mathrm{TECH}_{\mathrm{ij}}$ & $\begin{array}{c}0.416 \\
(1.93)\end{array}$ & $\begin{array}{r}0.417 \\
(1.95)\end{array}$ & $\begin{array}{c}0.768 \\
(0.80)\end{array}$ & $\begin{array}{r}-0.151 \\
(--1.98)\end{array}$ & $\begin{array}{r}-0.177 \\
(-2.27)\end{array}$ & $\begin{array}{l}-0.013 \\
(-0.11)\end{array}$ \\
\hline $\mathrm{EC}_{\mathrm{ij}}$ & $\begin{array}{c}0.264 \\
(0.49)\end{array}$ & $\begin{array}{c}0.202 \\
(0.38)\end{array}$ & $\begin{array}{r}0.582 \\
(0.80)\end{array}$ & $\begin{array}{l}1.244 \\
(6.55)\end{array}$ & $\begin{array}{c}1.232 \\
(6.33)\end{array}$ & $\begin{array}{r}1.961 \\
(6.96)\end{array}$ \\
\hline $\mathrm{ED}_{\mathrm{ij}}$ & $\begin{array}{r}-1.838 \\
(-3.79)\end{array}$ & $\begin{array}{r}-1.782 \\
(-3.70)\end{array}$ & $\begin{array}{l}-2.268 \\
(-3.41)\end{array}$ & $\begin{array}{c}--1.036 \\
(--5.99)\end{array}$ & $\begin{array}{r}-0.960 \\
(-5.42)\end{array}$ & $\begin{array}{r}-2.515 \\
(-9.61)\end{array}$ \\
\hline $\mathrm{HW}_{\mathrm{i}, \mathrm{j}}$ & $\begin{array}{l}-0.666 \\
(-0.99)\end{array}$ & $\begin{array}{r}-0.670 \\
(-1.00)\end{array}$ & $\begin{array}{r}-1.647 \\
(-1.15)\end{array}$ & $\begin{array}{l}-0.618 \\
(-2.61)\end{array}$ & $\begin{array}{l}-0.816 \\
(-3.37)\end{array}$ & $\begin{array}{r}0.709 \\
(2.00)\end{array}$ \\
\hline $\mathrm{SLG}_{\mathrm{ij}}$ & $\begin{array}{r}2.072 \\
(2.57)\end{array}$ & $\begin{array}{l}1.895 \\
(2.37)\end{array}$ & $\begin{array}{c}2.393 \\
(2.18)\end{array}$ & $\begin{array}{r}-0.441 \\
(-1.55)\end{array}$ & $\begin{array}{l}-0.339 \\
(-1.16)\end{array}$ & $\begin{array}{r}-0.488 \\
(-1.14)\end{array}$ \\
\hline $\begin{array}{l}\mathrm{R}^{2} \\
\text { D.F. }\end{array}$ & $\begin{array}{r}.35 \\
430\end{array}$ & $\begin{array}{r}.34 \\
430\end{array}$ & $\begin{array}{r}.36 \\
423\end{array}$ & $\begin{array}{r}.81 \\
429\end{array}$ & $\begin{array}{r}.80 \\
429\end{array}$ & $\begin{array}{r}.74 \\
422\end{array}$ \\
\hline
\end{tabular}

at-values are in parenthesis; $\mathrm{N}=441$ for total and white flows and $\mathrm{N}=434$ for black flows.

migrants. All component coefficients are expected to have positive signs since it is assumed that migrants prefer to have a greater quality of life in all aspects.

Lifetime white and black migrants are influenced by agricultural production $\left(\mathrm{AG}_{\mathrm{ij}}\right)$, education $\left(\mathrm{ED}_{\mathrm{ij}}\right)$ and state and local government $\left(\mathrm{SLG}_{\mathrm{ij}}\right)$ The negative value for $\mathrm{ED}_{\mathrm{ij}}$ and the positive coefficient for $\mathrm{AG}_{\mathrm{ij}}$ indicate the dominants of blacks in the South which in the past had relatively lower educational standards and more agricultural production. It is interesting to note that for lifetime whites individual status $\left(\mathrm{IS}_{\mathrm{ij}}\right)$ and technology $\left(\mathrm{TECH}_{\mathrm{ij}}\right)$ had a positive influence in their locational decisions whereas educational development $\left(\mathrm{ED}_{\mathrm{ij}}\right)$ and living conditions $\left(\mathrm{LC}_{\mathrm{ij}}\right)$ had a negative impact. This suggests that past migrants were 
more interested in job opportunities than in the quality of the surrounding environment.

White and black current migrants have significant coefficients for all indices except individual status $\left(\mathrm{IS}_{\mathrm{ij}}\right)$, state and local governments $\left(\mathrm{SLG}_{\mathrm{ij}}\right)$, and technology for blacks $\left(\mathrm{TECH}_{\mathrm{ij}}\right)$. White migration rates increase with superior living conditions $\left(\mathrm{LC}_{\mathrm{ij}}\right)$ whereas black migration was reduced. Whites moved away from areas of high technology whereas blacks were insignificant. Current black migration had a greater response to economic conditions $\left(\mathrm{EC}_{\mathrm{ij}}\right)$ and a much larger negative response to educational development $\left(E D_{i j}\right)$. Current whites moved away from areas of high welfare $\left(\mathrm{HW}_{\mathrm{ij}}\right)$ whereas blacks are attracted toward areas of high welfare. This may reflect the black migration from South to North in the sixties. Current migrants were not attracted to areas with economic equality $\left(\mathrm{IQ}_{\mathrm{ij}}\right)$, agricultural production $\left(\mathrm{AG}_{\mathrm{ij}}\right)$ and educational development $\left(E D_{i j}\right)$.

When comparing current and lifetime migrants it is apparent that living conditions $\left(\mathrm{LC}_{\mathrm{ij}}\right)$ and economic status $\left(\mathrm{EC}_{\mathrm{ij}}\right)$ were far more important for current migrants. Agricultural production $\left(\mathrm{AG}_{\mathrm{ij}}\right)$, technology $\left(\mathrm{TECH}_{\mathrm{ij}}\right)$, state and local government $\left(\mathrm{SLG}_{\mathrm{ij}}\right)$, and individual status $\left(\mathrm{IS}_{\mathrm{ij}}\right)$ were a more important influence for lifetime (past) migrants. Economic status $\left(\mathrm{EC}_{\mathrm{ij}}\right)$ had no influence on past migration rates but was a significant parameter in locational choice for current migrants.

\section{CONCLUSIONS}

The purpose of this paper has been to examine the relationship between migration in the United States and the quality of life. This aspect of the gross migration model has been ignored in the literature. This study has made use of recently published [Liu, 1974] quality of life indices for each state.

The theoretical framework developed in this study was based on an integration of utility maximization with investment behavior. This framework was then estimated using a recursive model by ordinary least squares regression analysis. This recursive technique helps to clarify the controversy over the influence of past migration on current migration patterns. Using 1970 census data for the gross out-migration flows from each of the nine census divisions to the various states as the dependent variables, the responsiveness to various measures of the quality of life was estimated. Equations were estimated for both current and lifetime migration flows classified by race.

The results indicate varying responses to the quality of life both across lifetime and current flows as well as between white and black migration. In the absence of direct information about the quality of life in the various states at an earlier time, the interpretation of the differences between lifetime and current flows is, of course, somewhat speculative. However, it is not unlikely that the relative standing of the various states 
with respect to the overall quality of life has remained fairly constant over time. The results indicated that, with the exception of black lifetime migrants, all migration flows tended to be toward destination with "higher" quality of life. The results for the component parts of the quality of life index indicates that both economic and other socio-environmental considerations play an important role in the locational decisions.

\section{FOOTNOTES}

1Sjaastad [1962] placed migration in an investment context in which individuals are more likely to migrate from region $\mathrm{A}$ to region $\mathrm{B}$, the greater the net benefit which accrues from such a movement.

2A study by Cebula and Vedder [1973] presented some results on net migration using crude proxies for the quality of life.

3Washington, D.C. is included as one of the possible destinations while Alaska and Hawaii have been omitted. The migration data were taken from Table 11 of U. S. Census of Population, Lifetime and Recent Migration, Subject Report 2D.

${ }^{4}$ For a discussion of discrete programming, see Baumol [1965, pp. 148-166].

iFollowing the work of Nelson (1959), several studies have examined this aspect of the migration model. See, for example, Greenwood [1969, 1970, 1972], Laber [1972], Levy and Wadycki [1973], and Renshaw [1974]. Greenwood referred to the accumulated migration from some origin (i) to some destination ( $j$ ) as the "migrant stock" to (j) from (i).

fiSee, for example, Sahota [1968], Greenwood
[1969], and Levy and Wadycki [1972].

'The purpose of this division is that: (1) it allows the dependent variable to be interpreted as a stochastic probability statement which makes it appropriate to estimate parameters using regression analysis and (2) it corrects for the bias caused by variations in the size of the out-migrating population. This is an allocation form of the dependent variable and follows that of Sjaastad [1961], Sahota [1967], Greenwood [1967], and Schwartz [1973].

The origin variables were calculated as the mean of the indexes for the states in each region.

9The Western states of Washington, Oregon, Colorado, Wyoming, and California have the highest quality-of-life index [see Liu (1974, p. 135) ] whereas the majority of the migration is from the populated Eastern states, hence the coefficients of the distance variable is positive due to the positive correlation between distance and the quality-of-life. This correlation results in a bias coefficient for distance and does not necessarily imply a non-negative relationship betwee distance and migration.

\section{REFERENCES}

Baumol, William J. Economic Theory and Operations Analysis, New Jersey, 1965.

Cebula, Richard J. and Vedder, Richard K. "A Note on Migration, Economic Opportunity and the Quality of Life," Journal of Regional Science, August, 1973, 13 (2): 205211.

Greenwood, Michael J. "An Analysis of the Determinants of Geographic Labor Mobility in the United States," Review of Economics and Statistics, May, 1969, 51 (2): 189-194.

"Lagged Response in the Decision to Migrate," Journal of Regional Science, 1970, 10 (3): 375-384.

"Lagged Response in the Decision to Migrate: A Reply," Journal of Regional Science, 1972, 12 (2): 311-324.

Laber, Gene. "Lagged Response in the Decision to Migrate: A Comment," Journal of Regional Science, 1972, 12 (2): 307-310.

Levy, M. B. and Wadycki, W. J. "Lifetime Versus One-Year Migration in Venezuela," Journal of Regional Science, December, 1972, 12 (3) : 407-415.

"The Influence of Family and Friends on Geographic Labor Mobility: An International Comparison," Review of Economics and Statistics, May, 1973, 60 (2): 198-203.
Liu, Ben-Chieh. "Variations in the Quality of Life in the United States, 1970," Review of Social Economy, October, 1974, 32 (2): 131147.

Nelson, Phillip. "Migration, Real Income and Information," Journal of Regional Science, 1959, 1 (1): 43-74.

Renshaw, Vernon. "A Note on Lagged Response in the Decision to Migrate," Journal of Regional Science, August, 1974, 14 (2): 273-280.

Sahota, Gian S. "An Economic Analysis of Internal Migration in Brazil," Journal of Political Economy, March/April, 1968, 76 (2): 218-245.

Schwartz, Aba. "Interpreting the Effect of Distance on Migration," Journal of Political Economy, September/October, 1973, 81 (5): 1153-1169.

Sjaastad, Larry A. "The Costs and Returns of Human Migration," Journal of Political Economy, October, 1962 (Supplement), 70: 80-93.

U. S. Census of Population. Lifetime and Recent Migration, Subject Report, 2D, 1970.

Wold, H. "Causality and Econometrics," Econometrica, 1954, 22: 162-177. 